\title{
Mitigation of Posttraumatic Stress Symptoms From Chronic Terror Attacks on Southern Israel
}

\author{
Nuriel S. Mor \\ Walden University \\ Kathryn L. Dardeck \\ Walden University
}

\begin{abstract}
Since 2000, the southern Israeli town of Sderot and neighboring rural region, Otef Aza, have been frequently exposed to nearly identical terror attacks by Hamas. While only a small minority of Otef Aza residents have been diagnosed with posttraumatic stress disorder (PTSD), more than a third of Sderot residents have been so diagnosed. Factors such as social cohesion and ideology may be the unique factors that protect Otef Aza residents from PTSD; however, a gap in the literature exists as to how these same factors might affect PTSD symptomology in Sderot residents. Orthodox religiosity has also been associated with reduced PTSD symptoms in Sderot; however, previous research on religiosity analyzed demographic characteristics and did not use a measure specifically assessing dimensions of religiosity. The purpose of this quantitative study was to examine the impact of community, ideology, and religiosity on PTSD symptoms among Sderot residents. A survey was distributed to a convenience sample of Sderot residents that 118 participants successfully completed. Standard multiple linear regression revealed that ideology, intrinsic religiosity, nonorganizational religious activity, and fulfillment of needs dimension of sense of community were significant predictors of PTSD symptomatology. Study findings suggested protective factors which could help a large portion of the population. The implications for positive social change for Sderot residents include increased positive interactions, sense of well-being, meaning, and value in their lives.
\end{abstract}

Keywords: PTSD, sense of community, religiosity, ideology, terror attacks, kibbutzim, Sderot, Otef Aza, Israel

\section{Introduction}

Since 2000, southern Israeli areas, including a town called Sderot, have been frequently attacked by Hamas, a Gaza-based terrorist organization (Gelkopf, Berger, Bleich, \& Silver, 2012). Accompanied by loud local warning sirens, more than 10,000 rockets and mortars have been fired on these regions resulting in casualties, injury, substantial property loss, and significant psychological distress (Stein et al., 2013). Residents of Sderot, which is located less than a mile from the Gaza border, are suffering distress to an even greater extent than had been estimated (Stein et al., 2013). It has been estimated that more than one third of Sderot residents aged 18-83 years met the criteria for posttraumatic stress disorder (PTDS; Stein et al., 2013). The criteria included at least one reexperiencing symptom, three avoidance symptoms, and two hyperarousal symptoms (Stein et al., 2013).

Please address queries to: Nuriel S. Mor, Walden University. Email: nuriel.mor@waldenu.edu 
More than one third of the population of Sderot has significant functional impairments as a result of the ongoing terror. Gelkopf et al. (2012) found that reexperiencing and arousal symptoms were extremely high and were reported by over three quarters of residents of Sderot.

A large portion of the population experiences levels of distress preventing them from working, studying, functioning within the family, or simply from enjoying life. Residents of Sderot spend significant periods of time hiding in shelters or trying to remain close to shelters with the knowledge that they only receive a 15-s warning before a rocket hits (Stein et al., 2013). The repeated race for shelter appears to have taken its toll (Gelkopf et al., 2012); lives of individuals in Sderot are meaningfully altered on a daily basis hiding in shelters and attempting to remain close to shelters at all hours (Stein et al., 2013). As such, there is a dire need to find protective factors that might mitigate the adverse psychological impact of this chronic exposure to terror attacks.

Research on protective factors in PTSD in civilians who have been exposed to ongoing incidents of terror for more than 10 consecutive years is still in its infancy (Besser, Neria, \& Haynes, 2009). Israel, a natural laboratory for studying the effects of ongoing traumatic incidents of terror on a civilian population, provides a research opportunity to examine psychological resiliency and potential protective factors against PTSD in the context of ongoing incidents of terror for more than 10 consecutive years (Stein et al., 2013). The present study was designed to narrow the gap in knowledge of the possible protective factors against PTSD among Sderot residents.

Otef Aza (which translates to Gaza envelope) is a rural region in southern Israel, whose residents have been exposed to the same continuous firing of rockets and mortars since 2000 as residents of the town Sderot. Otef Aza and Sderot are equidistant from the Gaza Strip and from where rockets have been fired. Researchers discovered that only 6.6\% of residents of Otef Aza had PTSD (Stein et al., 2013). In contrast, more than $35 \%$ of Sderot residents, a town with a nearly identical level of exposure to mortar attacks as Otef Aza, had PTSD. In addition, Stein et al. (2013) found that residents of Otef Aza did not show a dose-response relationship compared to residents of Sderot. In other words, increased exposure to trauma did not cause them to have increased PTSD symptomatology (Stein et al., 2013).

Unique characteristics of the Otef Aza communities seem to protect their residents from developing PTSD. The Otef Aza region is composed mainly of kibbutzim. A kibbutz (plural, kibbutzim) is a unique Israeli community cooperative based on socialistic values of equality and characterized by economic cooperation (Ben-Rafael, 2009). All of the property belongs to the collective, not to the individual. Each member has a different role such as farmer, physician, teacher, herdsman, and so on. Each member receives the same allowance from the kibbutz each month, no matter what his or her role. These communities share a socialistic ethos and are based on a model of social cohesiveness. Residents of these communities enjoy high solidarity, mutual support, and feel supported via the collective culture of their communities (Lev-Wiesel, 2003).

Researchers (Braun-Lewensohn \& Sagy, 2014; Gelkopf et al., 2012; Nuttman-Shwartz \& Dekel, 2009; Stein et al., 2013) have claimed that the Otef Aza communities are characterized by unique social cohesion, solidarity, socialistic ideology, and communal lifestyle. These features may be captured by two distinct concepts named sense of community and ideology. Sense of community was defined by McMillan and Chavis (1986) as a feeling that members of a certain group have of belonging and of being important to each other, and a shared belief that the needs of members will be met by the collective. Ideology is a broad concept that also refers to political and moral belief systems, which allow people to create a conceptual framework in which they can organize, interpret, understand, and construct meaning from the world (Oren \& Possick, 2010). These features might 
serve as protective factors against PTSD in the context of the ongoing incidents of terror experienced by residents of southern Israel (Braun-Lewensohn \& Sagy, 2014; Gelkopf et al., 2012; NuttmanShwartz \& Dekel, 2009; Stein et al., 2013). Researchers, however, have not tested the association between these features and PTSD symptoms in Sderot residents who suffer a greater rate of PTSD than the Otef Aza communities (Stein et al., 2013).

In different contexts than the ongoing terror attacks in Sderot, researchers (Kaplan, Matar, Kamin, Sadan, \& Cohen, 2005; Khamis, 2012; Moscardino, Scrimin, Capello, \& Altoè, 2010; Muldoon \& Downes, 2007) found that sense of community and ideology reduced the adverse psychological impact of terrorist attacks. Moscardino et al. (2010) found in the context of the 2004 Beslan, Russia, terrorist attack on a school that a higher sense of community was negatively correlated with adverse psychological impact following the traumatic incident (sense of community was associated with lower rates of depressive symptoms). Muldoon and Downes (2007) discovered in residents of postconflict Northern Ireland who experienced an ongoing political conflict that social identification and community solidarity were negatively associated with PTSD. Khamis (2012) found in a study that was conducted on residents of the Gaza Strip that ideology was negatively correlated with depression and anxiety. Khamis suggested that ideology might have served as a protector against anxiety and depression, and may have provided a belief system that allowed residents of the Gaza Strip to deal better with war-related stressors. Kaplan et al. (2005) concluded from a study that was conducted on residents of Gush-Katif, Kiryat-Arba, and Tel-Aviv, Israel, that ideological conviction was a major factor that improved coping of individuals in the face of ongoing conditions of conflict and threat. Kaplan et al. argued that ideology instills the exposure to conditions of ongoing threats with existential meaning, and concluded that nationalistic and ideological commitment are important protective factors against the negative psychological impact of ongoing conditions of conflict. Ideological commitment influences the subjective interpretation of traumatic experiences, the meaning attributed to them, and hence, the response (Kaplan et al., 2005).

Orthodox religiosity was also associated with reduced PTSD symptoms in the context of the ongoing terror attacks in Israel (Gelkopf et al., 2012; Palmieri, Canetti-Nisim, Galea, Johnson, \& Hobfoll, 2008). In the context of the Israel-Hezbollah war, Palmieri et al. (2008) found that ultrareligious individuals had lower PTSD rates compared to nonultrareligious individuals.

In the context of the ongoing terror attacks in Sderot, Stein et al. (2013) found that among residents of Sderot, people who reported that they were religious had lower rates of PTSD. However, Stein et al. (2013) found by analyzing the association between demographic characteristics and PTSD symptoms that people of Sderot who reported that they were religious had lower rates of PTSD, and not by a measure that assesses major dimensions of religiosity. Religiosity is composed of three dimensions: intrinsic religiosity, nonorganizational religious activity, and organizational religious activity (Koenig \& Büssing, 2010). Therefore, Stein et al. (2013) could not infer which component of religiosity is responsible for the protective effect among residents of Sderot.

A gap in the current literature exists regarding a lack of research that assesses sense of community, ideology, and religiosity by appropriate measures to investigate the relationship with PTSD symptoms for residents of Sderot. Therefore, the purpose of the present correlational study was to examine the impact of the independent variables sense of community, ideology, and religiosity on the dependent variable, PTSD symptoms, among residents of Sderot who have been exposed to terror attacks for more than 10 consecutive years.

The theoretical foundation of this study was the diathesis-stress model of PTSD (McKeever \& Huff, 2003). This comprehensive etiological model integrates up-to-date findings from both medical and 
psychological research. According to the diathesis-stress model of PTSD, three etiological pathways are associated with the disorder: residual stress, ecological diathesis, and biological diathesis (McKeever \& Huff, 2003). Residual stress comes from the severity of the trauma. Ecological diathesis includes personal, familial, cultural, social, and environmental factors. Biological diathesis includes all of the biological factors associated with the development of PTSD.

The diathesis-stress model of PTSD allows incorporation of many different ecological factors to explain the etiology of PTSD. The aim of this study was to assess the impact of the three different ecological factors (sense of community, religiosity, and ideology) on PTSD symptoms. According to the diathesis-stress model of PTSD (McKeever \& Huff, 2003), these ecological factors might influence the development of PTSD in chronic terror attack situations, and may allow researchers to explain the connection between these ecological factors and PTSD symptoms, if such a connection were found.

\section{Method}

\section{Participants}

The participants were a convenience sample of Sderot residents. Participants were recruited at Sderot's shopping center in the town center. Although by definition, this was a convenience sample and not a representative sample, recruitment was conducted at different times of day and several times per week, allowing the sample chosen to better reflect the target population from which they were drawn (Boxill, Chambers, \& Wint, 1997). The inclusion criteria were residents of Sderot who had been living in Sderot for the past 10 years and were above the age of 18. People who did not meet these criteria were excluded. Approval was secured from the first author's Institutional Review Board (Approval \# 0377723-16-29-04).

\section{Materials}

\section{Demographics}

A demographic questionnaire was used to assess basic information regarding participants' age, gender, and education.

\section{PTSD symptom level}

Participants' PTSD symptoms were measured by the PTSD Checklist-Civilian version (PCL-C; Weathers, Litz, Herman, Huska, \& Keane, 1994). The PCL-C, a well-validated 17-item measure assessing each symptom of PTSD, has been widely used to assess PTSD symptoms in adults above the age of 18 across the world, including in Israel (Dickstein et al., 2012; Ruggiero, Del Ben, Scotti, \& Rabalais, 2003). A total symptom severity score can be obtained by summing the scores from each of the 17 items that have response options ranging from 1 (not at all) to 5 (extremely; Ruggiero et al., 2003), and a total symptom severity score was used in this study. To receive a diagnosis of (provisional) PTSD according to the PCL-C based on Diagnostic and Statistical Manual of Mental Disorders $-I V$ criteria, the participant must have endorsed at least one reexperiencing symptom, three avoidance symptoms, and two hyperarousal symptoms (Gelkopf et al., 2012; Stein et al., 2013; Weathers et al., 1994).

In a study conducted on 392 college students, Ruggiero et al. (2003) found high correlations $(r>0.75)$ between PCL-C total scores and scores obtained on two well-established measures for PTSD named the Impact of Event Scale (Horowitz, Wilner, \& Alvarez, 1979) and the Mississippi Scale for PTSDCivilian version (MS-C; Vreven, Gudanowski, King, \& King, 1995). This high correlation between 
PCL-C, Impact of Event Scale, and Mississippi Scale for PTSD-Civilian version provides evidence for reasonable construct (convergent) validity.

\section{Sense of community}

Sense of community was measured by the Sense of Community Index (SCI; Perkins, Florin, Rich, Wandersman, \& Chavis, 1990). The SCI was developed to assess the four dimensions of sense of community—membership, influence, fulfillment of needs, and shared emotional connection—which were presented by McMillan and Chavis (1986). The SCI consists of 12 true/false items measuring psychological sense of community (Chipuer \& Pretty, 1999). Any of the four scores for each dimension can be obtained by summing the scores of each subscale, or a total sense of community score can be obtained by summing the scores from all items. The SCI is the most widely used measure of sense of community (Obst \& White, 2004). The SCI has been used in a variety of different populations across the world including in Israel (Huang \& Wong, 2014; McMillan \& Chavis, 1986; Moscardino et al., 2010; Obst \& White, 2004).

Construct validity of the SCI was established in several different studies (McCarthy, Pretty, \& Catano, 1990; Perkins et al., 1990; Pretty, 1990). Perkins et al. (1990) found that higher SCI scores were associated with participants who lived a longer time in their neighborhood and who had higher ratings of neighborhood block satisfaction. Pretty (1990) discovered an association between the SCI and support characteristics of university students' social environment. McCarthy et al. (1990) found an association between high SCI scores and high scores on well-being variables.

\section{Religiosity}

Religiosity was measured by the Duke University Religion Index (DUREL; Koenig \& Büssing, 2010), which was designed to measure the three major dimensions of religiosity: organizational religious activity, nonorganizational religious activity, and intrinsic religiosity (Bentley, Ahmad, \& Thoburn, 2014; Koenig \& Büssing, 2010). The DUREL has been used around the world, including Israel and the rest of the Middle East, and is a reliable measure of the three dimensions of religiosity (Bentley et al., 2014; Koenig \& Büssing, 2010). The DUREL is a five-item measure of religiosity. Either a total religiosity score can be obtained by summing the scores from each of the five, or three scores can be obtained by summing the scores of each subscale (Koenig \& Büssing, 2010).

Normative data of the DUREAL were obtained by administrating the DUREAL to almost 7,000 persons aged 18 to 90 participating in the National Institute on Aging's Established Population for Epidemiologic Studies in the Elderly, the National Institute of Mental Health's Epidemiologic Catchment Area Survey, and the National Institute of Mental Health-Supported Duke Hospital Study (Koenig \& Büssing, 2010). The overall scale has high test-retest reliability (intraclass correlation $=0.91$ ), high internal consistency (Cronbach's $\alpha=0.78-0.91$ ), and high convergent validity with other measures of religiosity ( $r=0.71-0.86$; Koenig \& Büssing, 2010). The DUREL has been used in more than 100 studies and had been translated into almost a dozen different languages (Spanish, Portuguese, Chinese, Romanian, Japanese, Thai, Persian/Arabic, German, Norwegian, Dutch, and Danish; Koenig \& Büssing, 2010).

\section{Ideology}

Ideology was measured by the measure of Oren and Possick (2010) for ideology. Oren and Possick developed and used a measure of ideology relevant to Israeli residents living next to Gaza. Three statements, each describing a different goal for living next to Gaza, are rated on a 4-point scale from 1 (not important at all) to 4 (very important). These goals are ideological (nationalist, socialist, and/or religious), strategic (protecting Israel by establishing an Israeli presence in the vicinity of the border with Gaza), and political (preventing the return of areas in the vicinity of Gaza to the Palestinians). 
A total ideology score can be obtained by summing the scores from the three items (Oren \& Possick, 2010). This measure had an internal reliability score $\alpha$ of 0.77 in a study that was conducted on 326 Israeli adult participants who lived in the vicinity of Gaza (Oren \& Possick, 2010).

\section{Procedure}

Over a 1-week period in the spring of 2016, 150 booklets containing all required forms were handed out to Sderot residents who agreed to participate in the study and who met the inclusion criteria. Of the 150 participants, 118 (78.66\%) successfully completed and returned all required forms. Upon the return of the forms from each participant, the researcher checked for missing data and alerted participants who did not complete their forms. Of the 150 participants, one did not bring back the forms, and 31 participants did not want to complete entire measures of variables. The rest of the participants successfully completed filling out their forms. Main analyses included using multiple linear regression.

The research questions follow:

Research Question 1: Does sense of community impact PTSD symptomatology in chronic terror attack situations?

Research Question 2: Does ideology impact PTSD symptomatology in chronic terror attack situations?

Research Question 3: Does religiosity impact PTSD symptomatology in chronic terror attack situations?

\section{Results}

\section{Descriptive Statistics}

Of those who successfully completed and returned all required forms, 71 (60.2\%) were males and 47 (39.8\%) were females. Table 1 summarizes the remaining demographic characteristics of the study sample. Means and standard deviations for the independent and dependent variables are presented in Table 2.

Consistent with previous researchers (Gelkopf et al., 2012; Stein et al., 2013) who examined the prevalence of PTSD symptoms among Sderot residents, 39 (33.05\%) of the 118 study participants met the criteria for (provisional) PTSD.

\section{Reliability}

Cronbach's $\alpha$ values were calculated to evaluate reliability and internal consistency of each scale. The SCI was found to have a Cronbach's $\alpha$ value of 0.77 . The DUREL was found to have a Cronbach's $\alpha$ value of 0.78 . The measure of Oren and Possick for ideology was found to have a Cronbach's $\alpha$ value of 0.70. The PCL-C was found to have a Cronbach's $\alpha$ value of 0.96. Perkins et al. (1990) reported that the SCI had an internal reliability score $\alpha$ of 0.80. Studies of the DUREL's psychometric properties have found Cronbach's $\alpha=0.78-0.91$ (Koenig \& Büssing, 2010). Oren and Possick (2010) reported that their ideology measure had an internal reliability score $\alpha$ of 0.77 . Bollinger, Cuevas, Vielhauer, Morgan, and Keane (2008) found that the PCL-C had a Cronbach's $\alpha$ value of 0.94. Keen, Kutter, Niles, and Krinsley (2008) and Morrill et al. (2008) reported that the PCL-C had a Cronbach's $\alpha$ value of 0.96 . 
Table 1: Demographic Characteristics of Study Sample ( $\mathrm{N}=118$ )

\begin{tabular}{lcc}
\hline Demographic & $n$ & $\%$ \\
\hline Age bracket & 25 & \\
18-27 & 17 & 21.2 \\
$28-37$ & 11 & 14.4 \\
$38-47$ & 19 & 9.3 \\
$48-57$ & 20 & 16.1 \\
$58-67$ & 14 & 17 \\
$68-77$ & 12 & 11.8 \\
$78-87$ & & 10.2 \\
Education & 7 & \\
Some elementary school & 11 & 5.9 \\
Elementary school & & 9.3 \\
$\quad$ graduate & 43 & \\
Some high school & 40 & 36.4 \\
High school graduate & 15 & 12.7 \\
Bachelor's degree & 2 & 1.7 \\
Master's degree & & \\
\hline
\end{tabular}

Table 2: Means and Standard Deviations for Continuous Variables

\begin{tabular}{lcccc}
\hline Variable & Minimum & Maximum & $M$ & $S D$ \\
\hline Sense of community & 0 & 12 & 7.75 & 3.026 \\
Ideology & 6 & 12 & 9.77 & 1.46 \\
Religiosity & 5 & 27 & 17.75 & 4.59 \\
Posttraumatic stress disorder & 17 & 75 & 36.74 & 13.11 \\
\hline
\end{tabular}

\section{Main Analyses}

A standard multiple linear regression (Pallant, 2013) was conducted to determine the strength and direction of the relationship between sense of community, ideology, and religiosity to PTSD symptomatology for residents of Sderot who have been exposed to terror attacks for more than 10 consecutive years. A second standard multiple linear regression was conducted to examine the relationship between dimensions of sense of community and religiosity with PTSD symptomatology among residents of Sderot.

\section{Sense of community}

The relationship between sense of community presented by SCI total score and PTSD symptomatology among Sderot residents was not found to be statistically significant, $t(113)=-0.49$, $p=.62, s r^{2}=0.01$.

\section{Fulfillment of needs and PTSD symptomatology}

The relationship between fulfilment of needs and PTSD symptomatology was found to be statistically significant, $t(108)=-2.33, p=0.02, s r^{2}=0.03$ uniquely accounting for $3 \%$ of the variance in PTSD symptomatology. As fulfillment of needs increased, PTSD symptomatology decreased among residents of Sderot who had been exposed to terror attacks for more than 10 consecutive years. The relationship between all other three dimensions of sense of community with PTSD symptomatology 
was not found to be statistically significant: membership, $t(108)=0.68, p=.49, s r^{2}=0.003$, influence, $t(108)=0.91, p=.36, s r^{2}=0.005$, and shared emotional connection, $t(108)=-0.72, p=.47 s r^{2}=0.003$.

\section{Ideology}

The relationship between ideology and PTSD symptomatology was found to be statistically significant, $t(113)=-2.98, p=.003, s r^{2}=0.06$, uniquely accounting for $6 \%$ of the variance in PTSD symptomatology. As ideology increases, PTSD symptomatology decreases.

\section{Religiosity}

The relationship between religiosity as measured by the DUREL total score and PTSD symptomatology was not found to be statistically significant, $t(113)=-1.82, p=0.07, s r^{2}=0.024$.

\section{Organizational religious activity, nonorganizational religious activity, and PTSD symptomatology}

The relationship between organizational religious activity and PTSD symptomatology was not found to be statistically significant, $t(108)=-1.02, p=.30, s r^{2}=0.007$. The relationship between nonorganizational religious activity and PTSD symptomatology was found to be statistically significant, $t(108)=2.02, p=.04, s r^{2}=0.02$, uniquely accounting for $2 \%$ of the variance in PTSD symptomatology. As nonorganizational religious activity increased, PTSD symptomatology increased among residents of Sderot who had been exposed to terror attacks for more than 10 consecutive years.

\section{Intrinsic religiosity and PTSD symptomatology}

The relationship between intrinsic religiosity and PTSD symptomatology was found to be statistically significant, $t(108)=-3.14, p=.002, s r^{2}=0.06$, uniquely accounting for $6 \%$ of the variance in PTSD symptomatology. As intrinsic religiosity increased, PTSD symptomatology decreased among residents of Sderot who had been exposed to terror attacks for more than 10 consecutive years.

\section{Discussion}

The purpose of this quantitative study was to examine the impact of sense of community, ideology, and religiosity on PTSD symptomatology among residents of Sderot, who had been exposed to frequent terror attacks for more than 10 consecutive years. The ongoing terror attacks experienced around the town of Sderot provided an opportunity to examine potential protective factors against PTSD in the context of chronic terror attacks for more than 10 consecutive years, and allowed for expanding terror research beyond the study of reactions to single terror attack incidents (Stein et al., 2013). The present study was conducted to gain an understanding of the impact of sense of community, ideology, and religiosity on PTSD symptoms among Sderot residents, in order to narrow the gap in knowledge of the possible protective factors against PTSD among Sderot residents. Identifying protective factors, as those examined in this study, could help a large portion of the Sderot population and be invaluable toward promoting positive social change (Gelkopf et al., 2012). Identifying more protective factors would reduce PTSD symptomatology and improve mental health for more than one third of residents of Sderot. In addition, the present study has larger potential implications; identifying protective factors as those examined in this study, could help other people in similar environments around the world.

After the data were screened and cleaned, a convenience sample of 118 Sderot residents was established. As noted standard multiple linear regression analysis was used to analyze the data. According to the overall results, ideology, intrinsic religiosity, nonorganizational religious activity, and the fulfillment of needs dimension of sense of community were significant predictors of PTSD 
symptomatology among residents of Sderot who had been exposed to terror attacks for more than 10 consecutive years.

\section{Sense of Community}

The first research question examined whether sense of community was a significant predictor of PTSD symptomatology among Sderot residents who had been exposed to terror attacks for more than 10 consecutive years. Sense of community, as measured by the SCI total score, was not a significant predictor of PTSD symptomatology among these residents of Sderot. In previous research, the relationship between sense of community and PTSD symptomatology was not examined among residents of Sderot. The findings of the current study are ostensibly inconsistent with previous research (e.g., Huang \& Wong, 2014; Moscardino et al., 2010; Muldoon \& Downes, 2007) conducted in contexts other than Sderot's ongoing terror attacks situation. Moscardino et al. (2010) found that in the context of the 2004 Beslan terrorist attack on a school that a higher sense of community was negatively correlated with depressive symptoms following the traumatic incident. Muldoon and Downes (2007) discovered that social identification and community solidarity were negatively associated with PTSD among residents of postconflict Northern Ireland who lived there during the civil conflict. Huang and Wong (2014) found that survivors of the 2008 Wenchuan earthquake who had a higher sense of community experienced higher levels of life satisfaction and lower levels of depression following the disaster.

The difference between previous studies conducted in other contexts than Sderot's ongoing terror attacks and this study might be the high level of traumatic exposure of residents of Sderot. The sample had been exposed to frequent terror attacks for more than 10 consecutive years. Sense of community, as measured by the SCI, might serve as a protective factor against PTSD in lower levels of exposure compared to 10 consecutive years of frequent terror attacks (Huang \& Wong, 2014; Moscardino et al., 2010). Bentley et al. (2014) observed that certain factors can reduce PTSD symptoms in people who experienced a low traumatic exposure and stop serving as protective factors in a higher traumatic exposure.

Previous researchers have not directly tested the association between sense of community and PTSD symptoms in Sderot residents (Stein et al., 2013). Past researchers (Gelkopf et al. 2012; Stein et al., 2013) found that residents of the rural region of Otef Aza who had been exposed to the same level of ongoing terror incidents as residents of the city of Sderot had a significantly lower rate of PTSD. Stein et al. (2013) found that $35.2 \%$ of Sderot residents had PTSD, while only $6.6 \%$ of Otef Aza residents had PTSD.

The Otef Aza region of Israel comprises mainly kibbutzim. Each member has a different role in the community, and each member receives the same allowance each month, no matter what his or her role. These communities are based on a model of social cohesiveness. Residents of these communities enjoy high solidarity, mutual support, and feel supported via the collective culture of their communities (Lev-Wiesel, 2003). Therefore, researchers (Braun-Lewensohn \& Sagy, 2014; Gelkopf et al., 2012; Nuttman-Shwartz \& Dekel, 2009; Stein et al., 2013) have hypothesized that these features, which can be captured partly by sense of community, might serve as a protective factor against PTSD from chronic terror attacks such as those experienced by residents of Sderot.

In this study, sense of community was measured by the SCI, which was developed to measure four dimensions of sense of community: membership, influence, fulfillment of needs, and emotional connection (Chipuer \& Pretty, 1999). The membership dimension includes emotional safety, sense of belonging, and identification with the group. The influence dimension determines whether 
individuals believe they can affect the community. The fulfillment of needs dimension is identified as a reinforcement dimension, which determines the extent to which members get their needs met through cooperation within members of the group. Shared emotional connection is based on shared history of struggles, success, and the ability of individuals to identify with this history (Chipuer \& Pretty, 1999). In the present study, the multiple linear regression analysis revealed that fulfillment of needs was a significant predictor of PTSD symptomatology among resident of Sderot who had been exposed to terror attacks for more than 10 consecutive years. As fulfillment of needs increases, PTSD symptomatology in this population appears to decrease.

The most fundamental process of kibbutzim is sharing resources so that the needs of each individual are met through the collective effort. The basic principle of kibbutzim is that each member contributes to the group in his or her different role, and every member receives an equitable share. The dependence of each member on other members to fulfill his or her needs is the basic principle of kibbutzim. Therefore, residents of kibbutzim feel supported via the collective culture of their communities (Lev-Wiesel, 2003). Apparently, this feature is captured by the fulfillment of needs dimension of sense of community. The fulfillment of needs is identified as a reinforcement dimension, in which association with the community is experienced as rewarding to individual members (Chipuer \& Pretty, 1999). Therefore, it is possible that the dimension of fulfillment of needs, rather than the other three dimensions of sense of community, successfully captured a unique, fundamental feature of the Otef Aza communities. This fulfillment of needs dimension may protect residents of Otef Aza from PTSD, and serve as a protective factor against PTSD for these Sderot residents.

According to the diathesis-stress model of PTSD, three etiological pathways are associated with PTSD: residual stress, ecological diathesis, and biological diathesis (McKeever \& Huff, 2003). Ecological factors might influence vulnerability to develop PTSD through impact on cognitive patterns, and on biological and brain reactions (McKeever \& Huff, 2003). Fulfillment of needs is an ecological factor that might influence the vulnerability to develop PTSD. A rewarding association with the community might reduce the distress accompanied with chronic terror attacks, and as a result, alleviate the adverse impact of ongoing exposure to terror attacks. In light of the diathesisstress model of PTSD, the ecological factor of fulfillment of needs might change cognitive patterns associated with perception of the threat from chronic terror attacks, and change the biological reaction to such a threat.

\section{Ideology}

The second research question examined whether ideology was a significant predictor of PTSD symptomatology among Sderot residents who had been exposed to terror attacks for more than 10 consecutive years. The relationship was significant; as ideology increased, PTSD symptomatology decreased. This finding is consistent with previous researchers (Garbarino, Kostelny, \& Dubrow, 1991; Kanagaratnam, Raundalen, \& Asbjørnsen, 2005; Kaplan et al., 2005; Khamis, 2012; Muldoon \& Wilson, 2001; Oren \& Possick, 2010; Punamäki, 1996) who found that ideology was associated with fewer PTSD symptoms among people exposed to terror-related stressors. In previous research, the correlation between ideology and PTSD symptomatology among residents of Sderot had not been researched.

Khamis (2012) found that among residents of the Gaza Strip, ideology was negatively correlated with depression and anxiety. Kaplan et al. (2005) assessed stress-related response in residents of GushKatif, Kiryat-Arba, and Tel-Aviv. Gush-Katif and Kiryat-Arba are settlements beyond the 1967 borders of Israel, and their residents have been exposed to daily warzone conditions. Tel Aviv is a 
relatively peaceful area located in the heart of Israel (Kaplan et al., 2005). Gush-Katif was composed exclusively of Jews with high levels of ideological commitment (Kaplan et al., 2005). Kaplan et al. found that although residents of Gush-Katif had the highest levels of exposure to terrorist attacks, they had a lesser degree of various stress-related responses than the other two groups. Kaplan et al. concluded that ideological conviction was a protective factor against adverse effects of ongoing conditions of conflict and threat as experienced by Gush-Katif residents.

In this study, residents of Sderot who had higher levels of ideology and who saw their residence in Sderot as an important ideological value had fewer PTSD symptoms. Kaplan et al. (2005) argued that ideology instills the exposure to conditions of ongoing threats with existential meaning; consequently, ideology is an important protective factor against the negative psychological impact of ongoing conditions of conflict as experienced in Israel. Garbarino et al. (1991) argued that ideology offers meaning impenetrable to extreme brutalization, as experienced in the Holocaust, and can play a role in shaping the consequences of chronic terror attacks. Punamäki (1996) suggested that ideology enables people to construct meaning out of terror attacks, and this process of construction of meaning protects against the adverse effects of exposure to terror attacks.

In light of the diathesis-stress model of PTSD (McKeever \& Huff, 2003), ideology is an ecological factor that may increase the ability to cope effectively in situations of ongoing terror attacks, perhaps by assigning meaning to these situations and therefore shaping the cognitive perception of the ongoing terror attacks. In accordance with the diathesis-stress model of PTSD, ideology via the etiological pathway of ecological diathesis, might influence the subjective interpretation of traumatic experiences, the meaning attributed to them, and hence, reduce PTSD symptomatology subsequent to ongoing terror attacks as experienced by Sderot residents.

\section{Religiosity}

The third research question examined whether religiosity was a significant predictor of PTSD symptomatology among Sderot residents who had been exposed to terror attacks for more than 10 consecutive years. Results indicated that the relationship between religiosity, as measured by the DUREL total score and PTSD symptomatology was not significant. However, intrinsic religiosity and nonorganizational religious activity were significant predictors of PTSD symptomatology. That is, as intrinsic religiosity increased, PTSD symptomatology decreased, and as nonorganizational religious activity increased, PTSD symptomatology increased. The relationship between organizational religious activity and PTSD symptomatology was not significant. In previous studies, researchers did not measure religiosity by a measure or instrument that assessed major dimensions of religiosity or the potential correlation with PTSD symptoms. They obtained information about religiosity by analyzing demographic data (Gelkopf et al. 2012; Stein et al., 2013).

The finding that as intrinsic religiosity increased PTSD symptomatology decreased is consistent with previous studies conducted in other contexts than the Sderot chronic terror attack situation (Aflakseir \& Coleman, 2009; Fischer, Greitemeyer, Kastenmüller, Jonas, \& Frey, 2006; Harrison, Koenig, Hays, Eme-Akwari, \& Pargament, 2001; Johnson \& Thompson, 2008; Schaefer, Blazer, \& Koenig, 2008). Schaefer et al. (2008) conducted a qualitative review of 23 selected studies that addressed the association of religious factors with posttraumatic stress and found that intrinsic religious orientation was the main useful construct in measuring religiosity in the association with the consequences of trauma. Schaefer et al. found that intrinsic religiosity was associated with decreased PTSD symptoms and lower severity of intrusive and avoidant posttraumatic-stress symptoms. Fischer et al. (2006) found that intrinsically religious people were less influenced by a high terror salience than nonreligious people. Intrinsic religiosity helped people to cope with threats 
of terrorism. Harrison et al. (2001) found that intrinsic religiosity was negatively related to depressive symptoms among cancer patients.

In the context of the Sderot situation of ongoing terror attacks, by analyzing the association between demographic characteristics and PTSD, Stein et al. (2013) found that people who reported that they were religious had lower rates of PTSD. In addition, a consistent finding across different researchers (Hobfoll et al., 2008; Korn \& Zukerman, 2011; Levav, Kohn, \& Billig, 2008; Palmieri et al., 2008; Somer, Maguen, Or-Chen, \& Litz, 2009; Schiff, 2006; Stein et al., 2013) was that Orthodox Jewish people had lower levels of PTSD symptoms than non-Orthodox Jewish residents of Israel, in the context of chronic Israeli wars and exposure to ongoing terror attacks.

As previously illustrated, according to the diathesis-stress model of PTSD (McKeever \& Huff, 2003), ecological factors might shape cognitive patterns and as a result influence perception of threats, and influence vulnerability of individuals to develop PTSD (McKeever \& Huff, 2003). Intrinsic religiosity is characterized by the striving for meaning and value. Intrinsic religious orientation refers to religion as an end of itself (Fischer et al., 2006). Consistent with the diathesis-stress model of PTSD, people who believe that the world is meaningful and can find a system of meaning in the face of a trauma that threatens to claim the world as meaningless; can in turn organize their world in the face of a trauma. As a result, these individuals might be less vulnerable to the impact of trauma (Lilly, Howell, \& Graham-Bermann, 2014).

As mentioned earlier, Stein et al. (2013) found by analyzing the association between demographic characteristics and PTSD symptoms that people of Sderot who reported that they were religious had lower rates of PTSD. Religiosity is composed of three dimensions: intrinsic religiosity, nonorganizational religious activity, and organizational religious activity (Koenig \& Büssing, 2010). Stein et al. (2013) did not infer which component of religiosity is responsible for the protective effect among residents of Sderot. The current study demonstrated that the intrinsic religiosity component is the component of religiosity that is responsible for the protective effects of religiosity against PTSD symptoms from ongoing terror attacks among Sderot residents.

Two findings reflect past research by Bentley et al. (2014). In this study, the relationship between organizational religious activity and PTSD symptomatology was not significant; moreover, as nonorganizational religious activity increased, PTSD symptomatology increased among these residents of Sderot. Bentley et al. investigated the influence of the three dimensions of religiosity on PTSD symptomatology in a sample of 59 Muslim, East African refugees living in the United States. The authors found that high levels of organizational religious activity and nonorganizational religious activity stopped having a protective effect as traumatic exposure increased. Bentley et al. found that high organizational religious activity was associated with reduced PTSD symptoms only for participants who reported a low traumatic exposure. For participants who had high rates of traumatic exposure, Bentley et al. found that the correlation between organizational religious activity and nonorganizational religious activity with PTSD symptomatology was positive. At high rates of traumatic exposure, as levels of organizational religious activity and nonorganizational religious activity increased, PTSD symptomatology increased (Bentley et al., 2014). Bentley et al. deduced that participants, who had higher levels of traumatic exposure and struggled with moderate PTSD symptoms, increased their private, unstructured religious activities as an attempt to reduce distress. Their findings and interpretation are appropriate to describe the current results. Residents of Sderot had a high level of traumatic exposure after being exposed to frequent terror attacks for more than 10 consecutive years. In high levels of exposure, in accordance with Bentley et al. (2014), organizational religious activity and nonorganizational religious activity are not sufficient or potent enough to reduce PTSD symptoms. At high levels of exposure, such as the situation in Sderot, a 
reverse process takes place: People who struggle with PTSD symptoms increase their nonorganizational, private, and unstructured religious activity as an attempt to reduce distress.

\section{Limitations}

\section{External validity}

Participants included a convenience sample rather than a representative sample. Therefore, the generalizability of the results is limited (Campbell \& Stanley, 1963).

\section{Internal validity}

PTSD symptom level was measured by the PCL-C. The gold standard for diagnosing PTSD is a structured clinical interview such as the Clinician-Administered PTSD Scale (Weathers et al., 2013). The PCL-C is designed to assess symptoms of PTSD and not to make lifetime diagnosis of PTSD. However, the Clinician-Administered PTSD Scale takes 45-60 min to administer, in comparison to the 5- to 10-min PCL-C. It should be noted that the PCL-C has been widely used by researchers, including those who studied the Sderot population, to assess PTSD symptomatology (Gelkopf et al., 2012; Stein et al., 2013).

\section{Recommendations for Further Research}

This study was a novel attempt to measure sense of community, ideology, and the three dimensions of religiosity and their relationship with PTSD symptoms among residents of Sderot who had been exposed to terror attacks for more than 10 consecutive years. An initial and promising finding was that as the fulfillment of needs dimension of sense of community increased, PTSD symptomatology decreased among Sderot residents. Fulfillment of needs was measured as a dimension of sense of community, and not as an independent variable. Future researchers should measure fulfillment of needs by a more elaborated measure designed to measure dimensions of this specific construct, and to further examine the relationship between fulfillment of needs and PTSD symptomatology among residents of Sderot.

In this study, organizational religious activity was not a significant predictor of PTSD symptomatology. Additionally, as nonorganizational religious activity increased, PTSD symptomatology increased. In accordance with previous research (Bentley et al., 2014), it was hypothesized that in high levels of traumatic exposure, organizational religious activity and nonorganizational religious activity would not be sufficient or potent enough to reduce PTSD symptoms. It was hypothesized that nonorganizational religious activity and PTSD symptomatology were positively correlated because at high levels of traumatic exposure, people who struggle with PTSD symptoms increase their nonorganizational, private, and unstructured religious activity to reduce distress (Bentley et al., 2014). This hypothesis should be examined among residents of Sderot in a future study by measuring and including levels of traumatic exposure as an independent variable.

The main limitation of the study is that the researcher used a convenience sample rather than a representative sample. Future researchers should strive to include a representative sample of residents of Sderot. This procedure is challenging to implement. One of the ways to achieve a representative sample is to use telephone interviews using in-region random digital methodology. 


\section{Implications for Positive Social Change}

This study revealed profound human suffering resulting from the ongoing conflict in Israel. About one third of the participants met the criteria for (provisional) PTSD. This study filled a gap in the research literature and supported positive social change by broadening knowledge of the factors that mitigate PTSD symptomatology from chronic terror attacks. Findings indicated that three main protective factors reduce PTSD symptoms for residents of Sderot who had been exposed to terror attacks for more than 10 consecutive years: higher levels of fulfillment of needs, ideology, and intrinsic religiosity. Findings have implications at the individual, organization, and community levels.

\section{Enhancing fulfillment of needs, ideology, and intrinsic religiosity}

On the individual level, this information is useful to Sderot residents, who can use this information to increase their fulfilment of needs level by increasing their cooperation with members of their group. Sderot residents could use this information to increase their ideology level by clarifying their own value, meaning, and importance in living in Sderot. In addition, Sderot residents could use this information to increase their awareness of the role and the protective effect of striving for meaning and value in their life, and to increase their intrinsic religiosity level.

On an organizational level, organizations should encourage cooperation and positive and rewarding interactions among residents of Sderot via different activities and settings. Organizations should encourage discussions, dialog, and debates in various settings concerning the ideological importance in living in Sderot, and concerning value and meaning of life.

At the community level, the high rate of PTSD among residents of Sderot suggests that many residents have trouble working, studying, functioning within the family, or simply enjoying life. Such a community also needs to financially support its distressed members. Sderot leaders should be encouraged to implement programs and activities designed to enhance fulfillment of needs, and ideology, and funding programs designed to enhance Sderot residents as they strive for meaning and value in their life.

\section{Conclusions}

Findings support previous research concerning the human suffering as a result of the ongoing conflict in Israel. One third of the participants met the criteria for (provisional) PTSD. The overall aim of this study was to identify protective factors against PTSD in the context of experiencing incidents of terror for more than 10 consecutive years. This study was a novel attempt to measure sense of community, ideology, and the three dimensions of religiosity, and to examine the relationship of these variables with PTSD symptoms among residents of Sderot. Residents with higher levels of fulfillment of needs, ideology, and intrinsic religiosity had fewer PTSD symptoms in this study. Higher levels of fulfillment of needs, ideology, and intrinsic religiosity might serve as protective factors against PTSD among residents of Sderot who have been exposed to terror attacks for more than 10 consecutive years. The implications of this study for positive social change for the residents of Sderot who have been exposed to chronic terror attacks include increased positive interactions, increased sense of well-being, and increased sense of meaning and value in their lives. 


\section{References}

Aflakseir, A., \& Coleman, P. G. (2009). The influence of religious coping on the mental health of disabled Iranian war veterans. Mental Health, Religion and Culture, 12, 175-190.

Ben-Rafael, E. (2009). What is a kibbutz? Jerusalem, Israel: Bialik Institute and Yad Tabenkin.

Bentley, J., Ahmad, Z., \& Thoburn, J. (2014). Religiosity and posttraumatic stress in a sample of East African refugees. Mental Health, Religion \& Culture, 17, 185-195.

Besser, A., Neria, Y., \& Haynes, M. (2009). Adult attachment, perceived stress, and PTSD among civilians exposed to ongoing terrorist attacks in Southern Israel. Personality and Individual Differences, 47, 851-857.

Bollinger, A. R., Cuevas, C. A., Vielhauer, M. J., Morgan, E. E., \& Keane, T. M. (2008). The operating characteristics of the PTSD Checklist in detecting PTSD in HIV+ substance abusers. Journal of Psychological Trauma, 7, 213-234.

Boxill, I., Chambers, C. M., \& Wint, E. (1997). Introduction to social research: With applications to the Caribbean. Kingston, Jamaica: University of the West Indies Press.

Braun-Lewensohn, O., \& Sagy, S. (2014). Community resilience and sense of coherence as protective factors in explaining stress reactions: Comparing cities and rural communities during missiles attacks. Community Mental Health Journal, 50, 229-234.

Campbell, D. T., \& Stanley, J. C. (1963). Experimental and quasi-experimental designs for research. Boston, MA: Houghton Mifflin.

Chipuer, H. M., \& Pretty, G. M. (1999). A review of the Sense of Community Index: Current uses, factor structure, reliability, and further development. Journal of Community Psychology, 27, 643-658.

Dickstein, B. D., Schorr, Y., Stein, N., Krantz, L. H., Solomon, Z., \& Litz, B. T. (2012). Coping and mental health outcomes among Israelis living with the chronic threat of terrorism. Psychological Trauma: Theory, Research, Practice, and Policy, 4, 392-399.

Fischer, P., Greitemeyer, T., Kastenmüller, A., Jonas, E., \& Frey, D. (2006). Coping with terrorism: The impact of increased salience of terrorism on mood and self-efficacy of intrinsically religious and nonreligious people. Personality and Social Psychology Bulletin, 32, 365-377.

Garbarino, J., Kostelny, K., \& Dubrow, N. (1991). What children can tell us about living in danger. American Psychologist, 46, 376-383.

Gelkopf, M., Berger, R., Bleich, A., \& Silver, R. C. (2012). Protective factors and predictors of vulnerability to chronic stress: A comparative study of 4 communities after 7 years of continuous rocket fire. Social Science \& Medicine,74, 757-766.

Harrison, M. O., Koenig, H. G., Hays, J. C., Eme-Akwari, A. G., \& Pargament, K. I. (2001). The epidemiology of religious coping: A review of recent literature. International Review of Psychiatry, 13, 86-93.

Hobfoll, S. E., Canetti-Nisim, D., Johnson, R. J., Palmieri, P. A., Varley, J. D., \& Galea, S. (2008). The association of exposure, risk, and resiliency factors with PTSD among Jews and Arabs exposed to repeated acts of terrorism in Israel. Journal of Traumatic Stress, 21, 9.

Horowitz, M. J., Wilner, N., \& Alvarez, W. (1979). Impact of Event Scale: A measure of subjective stress. Psychosomatic Medicine, 41, 209-221. 
Huang, Y., \& Wong, H. (2014). Impacts of sense of community and satisfaction with governmental recovery on psychological status of the Wenchuan earthquake survivors. Social Indicators Research, 117, 421-436.

Johnson, H., \& Thompson, A. (2008). The development and maintenance of post-traumatic stress disorder (PTSD) in civilian adult survivors of war trauma and torture: A review. Clinical Psychology Review, 28, 36-47.

Kanagaratnam, P., Raundalen, M., \& Asbjørnsen, A. E. (2005). Ideological commitment and posttraumatic stress in former Tamil child soldiers. Scandinavian Journal of Psychology, 46, $511-520$.

Kaplan, Z., Matar, M. A., Kamin, R., Sadan, T., \& Cohen, H. (2005). Stress-related responses after 3 years of exposure to terror in Israel: Are ideological-religious factors associated with resilience? Journal of Clinical Psychiatry, 66, 1146-1154.

Keen, S. M., Kutter, C. J., Niles, B. L., \& Krinsley, K. E. (2008). Psychometric properties of PTSD Checklist in sample of male veterans. Journal of Rehabilitation Research and Development, $45,465-474$.

Khamis, V. (2012). Impact of war, religiosity and ideology on PTSD and psychiatric disorders in adolescents from Gaza Strip and South Lebanon. Social Science \& Medicine, 74, 2005-2011.

Koenig, H. G., \& Büssing, A. (2010). The Duke University Religion Index (DUREL): A five-item measure for use in epidemiological studies. Religions, 1, 78-85.

Korn, L., \& Zukerman, G. (2011). Affective and behavioral changes following exposure to traumatic events: the moderating effect of religiosity on avoidance behavior among students studying under a high level of terror event exposure. Journal of Religion and Health, 50, 911-921.

Levav, I., Kohn, R., \& Billig, M. (2008). The protective effect of religiosity under terrorism. Psychiatry, 71, 46-58.

Lev-Wiesel, R. (2003). Indicators constituting the construct of "perceived community cohesion." Community Development Journal, 38, 332-343.

Lilly, M. M., Howell, K. H., \& Graham-Bermann, S. (2014). World assumptions, religiosity, and PTSD in survivors of intimate partner violence. Violence against Women, 21, 87-104.

McCarthy, M., Pretty, G. H., \& Catano, V. (1990). Psychological sense of community and student burnout. Journal of College Student Development, 31, 211-216.

McKeever, V. M., \& Huff, M. E. (2003). A diathesis-stress model of posttraumatic stress disorder: Ecological, biological, and residual stress pathways. Review of General Psychology, 7, 237250.

McMillan, D. W., \& Chavis, D. M. (1986). Sense of community: A definition and theory. Journal of Community Psychology, 14, 6-23.

Morrill, E. F., Brewer, N. T., O'Neill, S. C., Lillie, S. E., Dees, E. C., Carey, L. A., \& Rimer, B. K. (2008). The interaction of post-traumatic growth and post-traumatic stress symptoms in predicting depressive symptoms and quality of life. Psycho-Oncology, 17, 948-953.

Moscardino, U., Scrimin, S., Capello, F., \& Altoè, G. (2010). Social support, sense of community, collectivistic values, and depressive symptoms in adolescent survivors of the 2004 Beslan terrorist attack. Social Science \& Medicine, 70, 27-34.

Muldoon, O. T., \& Downes, C. (2007). Social identification and post-traumatic stress symptoms in post-conflict Northern Ireland. The British Journal of Psychiatry, 191, 146-149. 
Muldoon, O. T., \& Wilson, K. (2001). Ideological commitment, experience of conflict and adjustment in Northern Irish adolescents. Medicine, Conflict and Survival, 17, 112-124.

Nuttman-Shwartz, O., \& Dekel, R. (2009). Ways of coping and sense of belonging in the face of a continuous threat. Journal of Traumatic Stress, 22, 667-670.

Obst, P. L., \& White, K. M. (2004). Revisiting the sense of community index: A confirmatory factor analysis. Journal of Community Psychology 32, 691-705.

Oren, L., \& Possick, C. (2010). Is ideology a risk factor for PTSD symptom severity among Israeli political evacuees? Journal of Traumatic Stress, 23, 483-490.

Pallant, J. (2013). SPSS survival manual: A step by step guide to data analysis using IBM SPSS (5 ed.) Maidenhead, United Kingdom: McGraw-Hill.

Palmieri, P. A., Canetti-Nisim, D., Galea, S., Johnson, R. J., \& Hobfoll, S. E. (2008). The psychological impact of the Israel-Hezbollah War on Jews and Arabs in Israel: The impact of risk and resilience factors. Social Science \& Medicine, 67, 1208-1216.

Perkins, D., Florin, P., Rich, R., Wandersman, A., \& Chavis, D. (1990). Participation and the social and physical environment of residential blocks: Crime and community context. Journal of Community Psychology, 18, 83-115.

Pretty, G. H. (1990). Relating psychological sense of community to social climate characteristics. Journal of Community Psychology, 18, 60-65.

Punamäki, R. L. (1996). Can ideological commitment protect children's psychosocial well-being in situations of political violence? Child Development, 67, 55-69.

Ruggiero, K. J., Del Ben, K., Scotti, J. R., \& Rabalais, A. E. (2003). Psychometric properties of the PTSD Checklist-Civilian version. Journal of Traumatic Stress, 16, 495-502.

Schaefer, F. C., Blazer, D. G., \& Koenig, H. G. (2008). Religious and spiritual factors and the consequences of trauma: A review and model of the interrelationship. International Journal of Psychiatry in Medicine, 38, 507-524.

Schiff, M. (2006). Living in the shadow of terrorism: Psychological distress and alcohol use among religious and non-religious adolescents in Jerusalem. Social Science \& Medicine, 62, 23012312.

Somer, E., Maguen, S., Or-Chen, K., \& Litz, B. T. (2009). Managing terror: differences between Jews and Arabs in Israel. International Journal of Psychology, 44, 138-146.

Stein, N. R., Schorr, Y., Krantz, L., Dickstein, B. D., Solomon, Z., Horesh, D., \& Litz, B. T. (2013). The differential impact of terrorism on two Israeli Communities. American Journal of Orthopsychiatry, 83, 528-535.

Vreven, D. L., Gudanowski, D. M., King, L. A., \& King, D. W. (1995). The civilian version of the Mississippi Scale: A psychometric evaluation. Journal of Traumatic Stress, 8, 91-109.

Weathers, F. W., Blake, D. D., Schnurr, P. P., Kaloupek, D. G., Marx, B. P., \& Keane, T. M. (2013). The Clinician-Administered PTSD Scale for DSM-5 (CAPS-5). Retrieved from http://www.ptsd.va.gov/professional/assessment/adult-int/caps.asp

Weathers, F. W., Litz, B. T., Herman, D., Huska, J., \& Keane, T. (1994). The PTSD ChecklistCivilian version $(P C L-C)$. Boston, MA: National Center for PTSD. 
The Journal of Social, Behavioral, and Health Sciences is an open-access, peer-reviewed, online interdisciplinary journal focusing on research findings that address contemporary national and international issues. Its objectives are to (a) encourage dialogue between scholars and practitioners in the social, behavioral, and health sciences that fosters the integration of research with practice; (b) promote innovative models of interdisciplinary collaboration among the social, behavioral, and health sciences that address complex social problems; and (c) inform the relationship between practice and research in the social, behavioral, and health sciences.

Walden University Publishing: http://www.publishing.waldenu.edu 